\title{
Unit Root Analysis of Traffic Time Series in Toll
}

\section{Highways}

\author{
Antonio Sánchez Soliño and Antonio L. Lara Galera \\ Construction Department, Madrid Polytechnic University, Madrid 28040, Spain
}

\begin{abstract}
Concession contracts in highways often include some kind of clauses (for example, a minimum traffic guarantee) that allow for better management of the business risks. The value of these clauses may be important and should be added to the total value of the concession. However, in these cases, traditional valuation techniques, like the NPV (net present value) of the project, are insufficient. An alternative methodology for the valuation of highway concession is one based on the real options approach. This methodology is generally built on the assumption of the evolution of traffic volume as a GBM (geometric Brownian motion), which is the hypothesis analyzed in this paper. First, a description of the methodology used for the analysis of the existence of unit roots (i.e., the hypothesis of non-stationarity) is provided. The Dickey-Fuller approach has been used, which is the most common test for this kind of analysis. Then this methodology is applied to perform a statistical analysis of traffic series in Spanish toll highways. For this purpose, data on the AADT (annual average daily traffic) on a set of highways have been used. The period of analysis is around thirty years in most cases. The main outcome of the research is that the hypothesis that traffic volume follows a GBM process in Spanish toll highways cannot be rejected. This result is robust, and therefore it can be used as a starting point for the application of the real options theory to assess toll highway concessions.
\end{abstract}

Key words: Real options, unit root analysis, investment, highway concession, traffic.

\section{Introduction}

Most of road traffic models are based on the relationship between traffic volume and a number of explicative variables for which available information and prediction capacity are greater than for traffic itself. However, the use of time-series models may be an alternative tool to predict the traffic volume and to build a confidence interval for the forecast, when there are available data for traffic in a given road during a enough long period.

In this case, it can be assumed, in principle, that variations of traffic volume follow a GBM (geometric Brownian motion), which can be described in the following way:

$$
d \theta=a \theta d t+\sigma \theta d z
$$

where,

Corresponding author: Antonio Sanchez Soliño, professor, research fields: public economics and transportation. E-mail: asanoli@ciccp.es.

$$
\begin{array}{ll}
\theta: & \text { traffic volume } \\
d \theta: & \text { differential increment of traffic } \\
a: & \text { growth rate of traffic } \\
d t: & \text { differential time interval } \\
\sigma: & \text { traffic volatility } \\
d z: & \text { increment of a Wiener process }
\end{array}
$$

Starting from Eq. (1), and applying Itô's lemma [1], the process followed by the natural logarithm of $\theta$ can be described as:

$$
d(\ln \theta)=a^{\prime} d t+\sigma d z
$$

where, $\ln \theta$ is the natural logarithm of traffic and $a^{\prime}=a-\sigma^{2} / 2$.

On the right-hand side of Eq. (2), the parameter $a^{\prime}$ is a constant drift term or growth parameter. It means that the logarithm of traffic has a growth of $a^{\prime}$ per unit of time. Regarding the second term, $d z$ is the increment of a standard Wiener process, so that $d z=\varepsilon_{t}(d t)^{1 / 2}$, where, $\varepsilon_{t}$ is a variable which is normally distributed with zero mean and unit standard deviation [2]. This second term, $\sigma d z$, adds a noise or variability to the path followed by 
the logarithm of traffic. The amount of this noise is $\sigma$ times a standard Wiener process, so the process represented by Eq. (2) has a standard deviation of $\sigma$. This means that the variance rate (the variance per unit of time) of this process is $\sigma^{2}$ [3]. It is assumed that the parameter $\sigma$, which is called the traffic volatility, is also a constant.

The discrete version of Eq. (2) would be the following:

$$
\Delta(\ln \theta)=a^{\prime} \Delta t+\sigma \Delta z
$$

where,

$$
\begin{aligned}
& \mathrm{E}(\Delta z)=0 \quad[\text { expected value of } \Delta z] \\
& \mathrm{E}[\Delta(\ln \theta)]=a^{\prime} \Delta t \quad[\text { expected value of } \Delta(\ln \theta)] \\
& \mathrm{V}[\Delta(\ln \theta)]=\sigma^{2} \Delta t \quad[\text { variance of } \Delta(\ln \theta)]
\end{aligned}
$$

This means that the change in the logarithm of traffic is normally distributed over any time interval $\Delta t$ (with mean $a^{\prime} \Delta t$ and standard deviation $\sigma \sqrt{\Delta t}$ ), following a random walk with a drift. This assumption is frequently made for economic and financial variables. For stock prices, for example, the hypothesis of GBM is generally accepted, and it has been used for the development of the theory of options' valuation, since the initial works carried out by Black and Scholes [4] and Merton [5]. In the field of road traffic, this assumption has been made by Zhao et al. [6] to analyze the decision-making process in highway development.

However, the GBM hypothesis is not always evident. Pindyck and Rubinfeld [7], for example, have analyzed whether commodity prices follow this process. They found that, for very long time series (more than 100 years), detrended prices of crude oil and copper do not follow a random walk, but a mean-reverting process. However, and to the contrary, the hypothesis of a random walk cannot be rejected for the detrended prices of lumber.

In this paper, a test is performed for the hypothesis of a GBM for the evolution of traffic volume on toll highways. Series available for Spanish toll highways have been used, which, in most cases, cover a thirty-year period. In the following section a description is given of the methodology used for the analysis of the existence of unit roots in time series in general. The Dickey-Fuller approach has been applied, which is the most widely used test for this kind of analysis. Then this methodology has been applied for traffic series in Spanish toll highways and the results obtained have been examined. The limitations of the analysis carried out are considered and the possible application of the results is discussed. Finally, the main conclusions of the paper are summarized.

\section{Unit Roots Analysis of Time Series}

Suppose that $Y_{t}$ is a random variable which evolves over time following an autoregressive process that can be described as:

$$
Y_{t}=\rho Y_{t-1}+u_{t}
$$

where, $u_{t}$ is a random error term. Now, the parameter $\rho$ can be analyzed. If $\rho$ is equal to 1 , then it is said that a unit root exists, which means that $Y_{t}$ is a non-stationary variable. In the opposite case (if $\rho \neq 1$ ) the $Y_{t}$ variable would be stationary.

A constant drift term $\alpha$ can be added to Eq. (4), without changing the reasoning. The equation would then be:

$$
Y_{t}=\alpha+\rho Y_{t-1}+u_{t}
$$

Eq. (5) can be rewritten in the following way:

$$
Y_{t}-Y_{t-1}=\alpha+(\rho-1) Y_{t-1}+u_{t}
$$

The parameter $\rho$ in Eq. (6) can be estimated by using OLS (ordinary least squares), and calculating the t-statistic to test whether $\rho$ is significantly different from 1 . If the hypothesis that $\rho=1$ cannot be rejected, then it can be said that the process has a unit root, and therefore the $Y_{t}$ variable is non-stationary after detrending. However, if the true value of $\rho$ is 1 , then the OLS estimator is biased toward zero [7]. Then the use of OLS could lead us to incorrectly rejecting the non-stationarity hypothesis.

To solve this problem, Dickey and Fuller $[8,9]$ used a Monte Carlo simulation to calculate the correct critical values for the distribution of the t-statistic when 
$\rho=1$. The DF (Dickey-Fuller) test is subsequently the most widely used test to analyze the existence of a unit root in a given process.

To apply the DF test, Eq. (6) can be written as follows:

$$
\Delta Y_{t}=\alpha+\beta Y_{t-1}+u_{t}
$$

where, $\beta=\rho-1$.

Now, the OLS method is applied to estimate the value of the parameter $\beta$ (where the null hypothesis is that $\beta=0$ ) and to calculate its $\mathrm{t}$-statistic. The $\mathrm{t}$-statistic thus obtained is then compared with the critical values calculated by Dickey-Fuller. In fact, the critical values obtained by other authors based on the DF methodology are used. For example, McKinnon [10] obtained the following critical values.

If the $\mathrm{t}$-statistic obtained in our estimation is greater than the critical value, the hypothesis that $\beta=0$ cannot be rejected and then it is not possible to reject that the process is non-stationary after detrending. Observe that all critical values are negative. Therefore, if the $\mathrm{t}$-statistic obtained in our estimation is positive, the null hypothesis cannot be rejected (i.e., it cannot be rejected that the process is non-stationary).

In this kind of test, it is assumed that there is no serial correlation in the error term $u_{t}$. However, the process described by Eq. (7) may be non-stationary, even if there is serial correlation in $u_{t}$. As an extension of the methodology, serial correlation can be allowed now, by using the so-called ADF (augmented Dickey-Fuller) test. For that purpose, the model is expanded by adding the lagged dependent variable to the right-hand side of the equation, as follows:

$$
\Delta Y_{t}=\alpha+\beta Y_{t-1}+\sum_{j=1}^{m} \lambda_{j} \Delta Y_{t-j}+u_{t}
$$

where, $\lambda_{j}$ represent the $m$ parameters obtained in the regression analysis between the dependent variable $\Delta Y_{t}$ and the same dependent variable with a lag of $j$ periods (i.e., $\Delta Y_{t-j}$ ). For example, for annual data, if two lags are considered, the following expression would apply: $\Delta Y_{t}=\alpha+\beta Y_{t-1}+\lambda_{1} \Delta Y_{t-1}+\lambda_{2} \Delta Y_{t-2}+u_{t}$ where, two terms have been added, on the right-hand side of the equation, that include the dependent variable with a lag of one year and two years $\left(\Delta Y_{t-1}\right.$ and $\Delta Y_{t-2}$, respectively). The number of lags considered in the analysis depends on the decision of the analyst and the kind of problem being analyzed.

The regression analysis to determine the parameters in Eq. (8) is made using OLS. The t-statistic obtained for the parameter $\beta$ is then compared with the same critical values contained in the former (Table 1). Again, if the t-statistic obtained in our estimation is greater than the critical value, it cannot be rejected that $\beta=0$ and that the process is non-stationary after detrending.

\section{Results Obtained for Spanish Toll Highways}

In this section, the methodology described above is applied, in both versions (the Dickey-Fuller and the Augmented Dickey-Fuller tests), for traffic series in Spanish toll highways. As a starting point, data collected by the public authority [11] which is in charge of the supervision of national toll highways are used. These highways have an average length of 134 $\mathrm{km}$, and all of them are managed by private companies under concession contracts. These private companies are obliged to provide the relevant data to the said public authority, and this is published, and is available for researchers or for any person with an interest in the matter.

The AADT (annual average daily traffic) has been used in the research. By using annual data, the problem of seasonality in traffic volumes is avoided. The collected data are included in Appendix 1 in this paper.

Table 1 Critical values for t-statistic in DF unit roots tests.

\begin{tabular}{lll}
\hline Sample size & Significance level $=5 \%$ & $\begin{array}{l}\text { Significance } \\
10 \%\end{array}$ \\
\hline 25 & -3.00 & -2.63 \\
50 & -2.93 & -2.60 \\
100 & -2.89 & -2.58 \\
$\infty$ & -2.86 & -2.57 \\
\hline
\end{tabular}


In order to perform the DF test, the following variable is used: $Y_{t}=\ln \left(\theta_{t}\right)$, where $\theta_{t}$ is the volume of traffic, in terms of AADT. Therefore, Eq. (7) is applied, where $\Delta Y_{t}=\ln \left(\theta_{t} / \theta_{t-1}\right)$. A regression analysis has been performed, using OLS to obtain the estimation of the parameter $\beta$ and the t-statistic for that estimation for each highway. The results for the relevant t-statistics are included in the third column of Table 2.

These results can be compared with the critical values in Table 1. As the period of analysis is around thirty years in most cases, the critical values can be taken for a sample size equal to 25 in Table 1 . It can then be seen that for significance levels of $5 \%$ and $10 \%$, the null hypothesis (i.e., $\beta=0$ ) cannot be rejected for any of the highways analyzed. This means that, according to the DF test, the hypothesis that traffic in Spanish toll highways follows a GBM process cannot be rejected.

The ADF test has also been performed, by using Eq. (8), where once again $\Delta Y_{t}=\ln \left(\theta_{t} / \theta_{t-1}\right)$. One lag and two lags have been taken for the analysis, which is considered to be sufficient in view of the results obtained.

With one lag, the regression analysis is applied using the following expression:

$$
\Delta\left(\ln \theta_{t}\right)=\alpha+\beta\left(\ln \theta_{t-1}\right)+\lambda_{1} \Delta\left(\ln \theta_{t-1}\right)+u_{t}(10)
$$

Here the parameter $\beta$ is estimated and its t-statistic is then calculated.
With two lags, the relevant expression is analogous, and again, the estimation of the parameter $\beta$ is carried out.

The relevant t-statistics for each highway are included in the fourth and fifth columns in Table 2. As it can be observed, making a comparison with the critical values in Table 1 , the null hypothesis cannot be rejected for any of the highways and, subsequently, it cannot be rejected that traffic follows a GBM process. On the other hand, there is not a clear pattern in the values of the t-statistic with one lag and with two lags. For some highways, the t-statistic is nearer the critical value with two lags than with one lag, and in other cases it is the other way round.

\section{Limitations of the Analysis and Application of the Results}

According to the results obtained in the research described in this paper, the GBM hypothesis for traffic volume cannot be rejected. However, one should be aware of the limitations of the analysis. These results provide only weak evidence in favor of the hypothesis that traffic actually follows a GBM. In fact, the results could be different for longer periods of analysis, as the results obtained by Pindyck and Rubinfeld [7] show for the case of commodity prices. Unfortunately, longer traffic series are not normally available.

Table 2 Results of unit roots tests for traffic series.

\begin{tabular}{lllll}
\hline Name of highway & Period of analysis & DF test t-statistic & ADF test (one lag) t-statistic & ADF test (two lags) t-statistic \\
\hline Villalba-Adanero & $1974-2007$ & 0.6692 & 0.7843 & 0.8895 \\
Zaragoza-Mediterráneo & $1976-2007$ & -1.5419 & -0.8040 & -1.2278 \\
Sevilla-Cádiz & $1974-2007$ & 1.1856 & 0.3834 & 0.0468 \\
Montmeló-La Junquera & $1974-2007$ & 0.6792 & -0.5228 & -0.2624 \\
Barcelona-Tarragona & $1974-2007$ & -1.4503 & -1.7321 & -1.2479 \\
Montmeló-Papiol & $1978-2007$ & -0.7704 & -1.2694 & -1.4408 \\
Bilbao-Zaragoza & $1978-2007$ & 0.8923 & -0.4104 & -0.1090 \\
Burgos-Armiñón & $1978-2007$ & -2.0183 & -0.6922 & -0.3636 \\
León-Campomanes & $1983-2007$ & 0.2918 & -1.3950 & -1.1522 \\
Tarragona-Valencia & $1974-2007$ & -0.3193 & -0.9579 & -0.8513 \\
Valencia-Alicante & $1976-2007$ & -1.3442 & -0.8213 & -0.1557 \\
\hline
\end{tabular}


Nevertheless, the results are robust, in the sense that the relevant tests have been applied to all the national toll highways in Spain, and the hypothesis could not be rejected in any of these. Furthermore, it would be possible to generalize the results, since there are various types of highways in the sample used: some of these are coastal highways (with a clearly tourist nature), others are interurban highways and, finally, other highways have some of the features of metropolitan transportation networks.

Another limitation of the analysis is the assumption of a constant volatility of traffic. For the estimation of this volatility, historic data in Spanish toll highways have been used. A simple procedure to calculate traffic volatility is as follows:

Suppose a traffic series for a certain highway: $\theta_{1}, \theta_{2}$, $\theta_{3}, \ldots \theta_{n}$, where $\theta_{i}$ is the traffic volume in year $i$. Then the following variable is defined: $x_{i}=\Delta \ln \left(\theta_{i}\right)=\ln \left(\theta_{i}\right)$ $\left.\theta_{i-1}\right)$, and $\bar{x}$ is obtained as the mean of $x_{1}, x_{2}, \quad x_{n}$. The volatility of traffic, defined as the standard deviation of the sample $x_{1}, x_{2} \ldots x_{n}$, would then be as follows:

$$
\sigma=\sqrt{\frac{1}{n-1} \sum_{i=1}^{i=n}\left(x_{i}-\bar{x}\right)^{2}}
$$

Using this definition, the volatility for traffic in each toll highway in Spain has been obtained, starting from data contained in Appendix 1. It has been assumed that the volatility in each highway remains constant, but it may in fact change over time. However, it has been observed that traffic volatility in toll highways is greater over the first years of the concession, before becoming smaller and more stabilized. This means that, if with sufficiently long time series (say twenty years) the hypothesis of a constant volatility in the future can be assumed. In the present case, it has been obtained that the volatility of traffic in Spanish toll highways (for annual data) tends towards an average value close to 0.075 .

The hypothesis of the Geometric Brownian Motion given by Eq. (1) can be applied for the valuation of toll highways concessions. In this kind of concession, both the forecast of future traffic and the measure of the risks involved are essential for the appraisal of the business. The calculation of the value of the volatility of traffic (probably the most important source of uncertainty in a toll highway) allows for using the model to build a confidence interval for the traffic forecast.

Besides, the terms of reference in toll highway concessions (and the concession contracts) often contain certain clauses that allow for a degree of operational flexibility in the management of the business. The valuation of this kind of clauses in contracts can be carried out using a real options approach, a methodology based on the development of the theory of financial options. Under this approach, traffic volume on the highway (for which a GBM process is assumed) is used as the underlying asset in an option contract. Options that are embedded in the concession agreement are thus calculated as a derivative of the traffic volume. This means that traffic is treated as the source of uncertainty that determines the value of the options.

The possible exercise of this series of rights represents an added value for the project which is not captured by the traditional procedures of valuation. The habitual practice of calculating the NPV (net present value) of the project by means of the discount of cash flows, leads to erroneous results when the project incorporates a certain degree of flexibility.

Therefore, the theory of real options is an alternative tool for the correct valuation of toll highway concessions, under the hypothesis that the variations of traffic volume follow a GBM like the one described in former Eq. (1).

\section{Conclusions}

The main result of the research is that the hypothesis that traffic follows a generalized Wiener process (or so-called Geometric Brownian Motion) in Spanish toll highways cannot be rejected. In other words, the evidence found leads to the conclusion that the non-stationarity hypothesis for traffic cannot be 
rejected, but have to bear in mind that this is only a weak evidence in favor of the hypothesis that traffic actually follows a non-stationary process.

The GBM hypothesis can be applied to the valuation of toll highway concessions. The terms of contracts in toll highway concessions often contain certain clauses that allow for a degree of operational flexibility in the management of the business. The valuation of these kinds of clauses in contracts can be carried out using a real options approach. The full description of this methodology is beyond the scope of this paper [12], but some of the options that usually appear in concession contracts have been quoted: minimum traffic guarantees (traffic floors), maximum traffic limitations (traffic caps), extension of the concession, anticipated reversion, granting of public subsidies, public participation loans, etc.. These mechanisms reduce the variability of the project cash-flows, and allow for more flexibility and a better management of the concession based on the contingency of future events. The theory of real options is an alternative tool for the correct valuation of highway concessions when these kinds of rights are present in concession contracts, and the results of our research allow for the application of this methodology under the assumption that the evolution of traffic volume follows a Geometric Brownian Motion.

\section{References}

[1] K. Itô, On stochastic differential equations, Memoirs of the American Mathematical Society 4 (1951) 1-51.

[2] A. K. Dixit and R. S. Pindyck, Investment under Uncertainty, Princeton University Press, Princeton, New Jersey, 1994.
[3] J. C. Hull, Options, Futures and Other Derivatives, Pearson Prentice Hall, 6th ed., Upper Saddle River, New Jersey, 2006.

[4] F. Black and M. Scholes, The pricing of options and corporate liabilities, Journal of Political Economy 81 (1973) 637-654.

[5] R. C. Merton, Theory of rational option pricing, Bell Journal of Economics and Management Science 4 (1973) 141-183.

[6] T. Zhao, S. K. Sundararajan and C. Tsen, Highway development decision-making under uncertainty: a real options approach, Journal of Infrastructure Systems 10 (1) (2004) 23-32.

[7] R. S. Pindyck and D. L. Rubinfeld, Econometric Models and Economic Forecasts (4th ed.), McGraw-Hill, Boston, 1998.

[8] D. A. Dickey and W. A. Fuller, Distribution of the estimators for autoregressive time-series with a unit root, Journal of the American Statistical Association 74 (1979) 427-431.

[9] D. A. Dickey and W. A. Fuller, Likelihood Ratio Statistics for Autoregressive Time Series with a Unit Root, Econometrica 49 (1981) 1057-1072.

[10] J. McKinnon, Critical Values for Cointegration Tests, Discussion Paper 90.4, University of California, San Diego, 1990.

[11] Government Office for Toll Highways, 2007 Report, Transportation and Public Works Department, Madrid, 2008. (in Spanish)

[12] A. L. L. Galera and A. S. Soliño, A real options approach for the valuation of highway concessions, Transportation Science 44 (3) (2010) 416-427. 


\section{Appendix 1 Traffic Data}

AADT (annual average daily traffic) in Spanish Toll Highways

\begin{tabular}{|c|c|c|c|c|c|c|c|c|c|c|}
\hline $\begin{array}{l}\text { Year } \\
\text { /Hig- } \\
\text { hway }\end{array}$ & $\begin{array}{l}\text { Villalba-A } \\
\text { danero }\end{array}$ & $\begin{array}{l}\text { Zaragoza-M } \\
\text { editerráneo }\end{array}$ & $\begin{array}{l}\text { Sevilla Montmeló-L } \\
\text {-Cádiz a Junquera }\end{array}$ & $\begin{array}{l}\text { Barcelona-T } \\
\text { arragona }\end{array}$ & $\begin{array}{l}\text { Montmel } \\
\text { ó-Papiol }\end{array}$ & $\begin{array}{l}\text { Bilbao-Z } \\
\text { aragoza }\end{array}$ & $\begin{array}{l}\text { Burgos-Ar } \\
\text { miñón }\end{array}$ & $\begin{array}{l}\text { León-Camp } \\
\text { omanes }\end{array}$ & $\begin{array}{l}\text { Tarragona } \\
\text {-Valencia }\end{array}$ & $\begin{array}{l}\text { Valencia- } \\
\text { Alicante }\end{array}$ \\
\hline 1974 & 7,258 & & $3,171 \quad 14,728$ & 15,377 & & & & & 5,603 & \\
\hline 1975 & 7,817 & & $3,382 \quad 13,354$ & 15,367 & & & & & 5,776 & \\
\hline 1976 & 8,168 & 5,276 & $3,017 \quad 13,002$ & 16,630 & & & & & 6,002 & 3,563 \\
\hline 1977 & 6,690 & 6,179 & $3,039 \quad 13,925$ & 19,760 & & & & & 6,870 & 4,148 \\
\hline 1978 & 7,796 & 6,439 & $3,470 \quad 15,823$ & 22,811 & 9,389 & 4,689 & 2,479 & & 7,524 & 5,183 \\
\hline 1979 & 8,455 & 7,001 & $3,681 \quad 15,859$ & 23,659 & 6,875 & 4,169 & 3,604 & & 7,828 & 5,874 \\
\hline 1980 & 8,326 & 7,053 & $3,77415,026$ & 24,565 & 7,480 & 4,606 & 4,060 & & 7,773 & 6,059 \\
\hline 1981 & 8,380 & 6,920 & $3,999 \quad 15,557$ & 23,575 & 6,470 & 4,681 & 5,622 & & 7,590 & 6,258 \\
\hline 1982 & 8,355 & 6,761 & $3,929 \quad 15,948$ & 23,613 & 6,723 & 4,754 & 4,966 & & 7,455 & 6,147 \\
\hline 1983 & 8,283 & 6,607 & $3,629 \quad 15,934$ & 23,166 & 6,861 & 4,374 & 4,611 & 2,494 & 7,233 & 6,071 \\
\hline 1984 & 8,452 & 6,489 & $3,417 \quad 16,478$ & 23,597 & 6,944 & 4,281 & 4,970 & 2,049 & 7,178 & 6,124 \\
\hline 1985 & 8,810 & 6,659 & $3,632 \quad 17,099$ & 24,857 & 7,352 & 4,275 & 5,142 & 2,141 & 7,596 & 6,933 \\
\hline 1986 & 9,478 & 7,181 & $3,959 \quad 18,892$ & 27,154 & 27,404 & 4,433 & 5,487 & 2,275 & 8,514 & 7,240 \\
\hline 1987 & 10,360 & 8,119 & $4,52521,282$ & 30,793 & 31,558 & 4,874 & 5,994 & 2,445 & 9,707 & 8,316 \\
\hline 1988 & 11,420 & 9,387 & $5,282 \quad 23,671$ & 34,963 & 42,998 & 5,617 & 6,832 & 2,768 & 10,873 & 9,376 \\
\hline 1989 & 12,929 & 11,423 & $6,35026,296$ & 39,624 & 51,004 & 6,494 & 7,777 & 3,233 & 12,336 & 10,563 \\
\hline 1990 & 14,005 & 12,127 & $6,83526,660$ & 40,618 & 52,226 & 6,870 & 8,294 & 3,661 & 12,501 & 12,027 \\
\hline 1991 & 15,610 & 12,327 & $7,79127,802$ & 42,080 & 54,489 & 7,118 & 8,954 & 4,254 & 13,043 & 12,663 \\
\hline 1992 & 16,415 & 12,174 & $9,21428,488$ & 41,379 & 49,997 & 7,052 & 9,403 & 4,256 & 12,894 & 12,595 \\
\hline 1993 & 16,504 & 11,425 & $8,00528,124$ & 40,152 & 45,884 & 6,956 & 9,680 & 4,199 & 12,336 & 12,085 \\
\hline 1994 & 16,628 & 10,958 & $7,97828,554$ & 41,123 & 46,960 & 6,930 & 10,172 & 4,583 & 12,469 & 12,301 \\
\hline 1995 & 17,358 & 11,309 & $7,64828,509$ & 43,270 & 48,724 & 7,013 & 11,026 & 4,680 & 12,907 & 12,313 \\
\hline 1996 & 17,866 & 11,027 & $7,43427,076$ & 43,530 & 52,453 & 7,038 & 11,430 & 4,718 & 13,070 & 12,423 \\
\hline 1997 & 18,687 & 11,423 & $7,828 \quad 29,021$ & 45,677 & 58,635 & 7,343 & 12,198 & 4,995 & 14,186 & 13,207 \\
\hline 1998 & 20,715 & 12,377 & $10,10130,717$ & 47,799 & 63,220 & 8,082 & 13,696 & 5,659 & 16,692 & 16,271 \\
\hline 1999 & 22,918 & 13,350 & $11,82533,815$ & 47,089 & 70,219 & 9,002 & 15,161 & 6,320 & 19,092 & 18,987 \\
\hline 2000 & 24,325 & 14,870 & $13,300 \quad 35,955$ & 51,278 & 83,935 & 10,623 & 16,605 & 6,642 & 20,453 & 21,225 \\
\hline 2001 & 25,482 & 15,206 & $15,21837,901$ & 53,721 & 90,218 & 11,742 & 18,062 & 7,433 & 22,004 & 23,409 \\
\hline 2002 & 27,238 & 15,594 & $16,53440,464$ & 55,994 & 92,636 & 12,196 & 19,348 & 7,679 & 22,796 & 24,968 \\
\hline 2003 & 28,662 & 15,464 & $17,89741,756$ & 57,782 & 95,712 & 12,844 & 20,101 & 8,048 & 23,396 & 26,640 \\
\hline 2004 & 30,301 & 15,350 & $19,64243,324$ & 59,053 & 99,460 & 13,503 & 21,072 & 8,736 & 23,932 & 27,302 \\
\hline 2005 & 30,770 & 14,744 & $21,85944,918$ & 60,342 & 111,353 & 13,542 & 21,206 & 9,006 & 23,482 & 28,180 \\
\hline 2006 & 32,998 & 15,273 & $24,24447,122$ & 63,683 & 115,607 & 14,177 & 22,209 & 9,683 & 25,215 & 29,207 \\
\hline 2007 & 34,414 & 15,541 & $24,95149,180$ & 66,217 & 118,519 & 14,712 & 23,937 & 10,288 & 25,110 & 29,411 \\
\hline
\end{tabular}

